\title{
Gastrointestinal manifestations and management of anisakiasis
}

\author{
Lubna Madi MD, Massud Ali MD FRCPC, Philippe Legace-Wiens MD FRCPC, Donald R Duerksen MD FRCPC
}

\begin{abstract}
A nisakiasis is a parasitic disease of the gastrointestinal tract acquired by ingestion of raw fish containing stage 3 larvae. In the present report, we describe a patient who frequently ate raw fish who presented with acute onset of epigastric abdominal pain and a peripheral blood eosinophilia. His symptoms resolved with endoscopic removal of the nematode. Given the increasing consumption of raw fish in Western cultures, anisakiasis should be considered in patients with abdominal pain and a history of raw fish consumption.
\end{abstract}

\section{CASE PRESENTATION}

A 61-year-old, previously healthy man presented to the emergency department with a one-day history of severe constant, burning epigastric pain associated with nausea and vomiting. A dietary history revealed that he frequently consumed raw fish including salmon, trout, sushi and sashimi. His most recent ingestion was two weeks before presentation when he ate raw frozen salmon. On physical examination, he exhibited mild tenderness in his epigastrium.

Significant laboratory results demonstrated a white blood cell count of $11.3 \times 10^{9} / \mathrm{L}$ with $13.3 \%$ eosinophils. An infused abdominal computed tomography scan showed mild small bowel dilation and circumferential wall thickening of the mid small bowel over a distance of $8.5 \mathrm{~cm}$, and some thickening of the antral wall of the stomach.

Upper endoscopy revealed a serpiginous helminth $2.0 \mathrm{~cm}$ long with one end burrowed into the mucosal layer of the antrum (Figure 1). The surrounding mucosa was edematous and erythematous. Movement of the tail of this helminth was observed at endoscopy. The nematode was grasped gently with a biopsy forceps and freed from the mucosa (Figure 2). It was retrieved and sent to the parasitology laboratory, where it was definitively identified as Anisakis simplex, a gastrointestinal nematode. The endoscopy also revealed gastric erosions that had the appearance of having been infiltrated by a helminth (Figure 1).

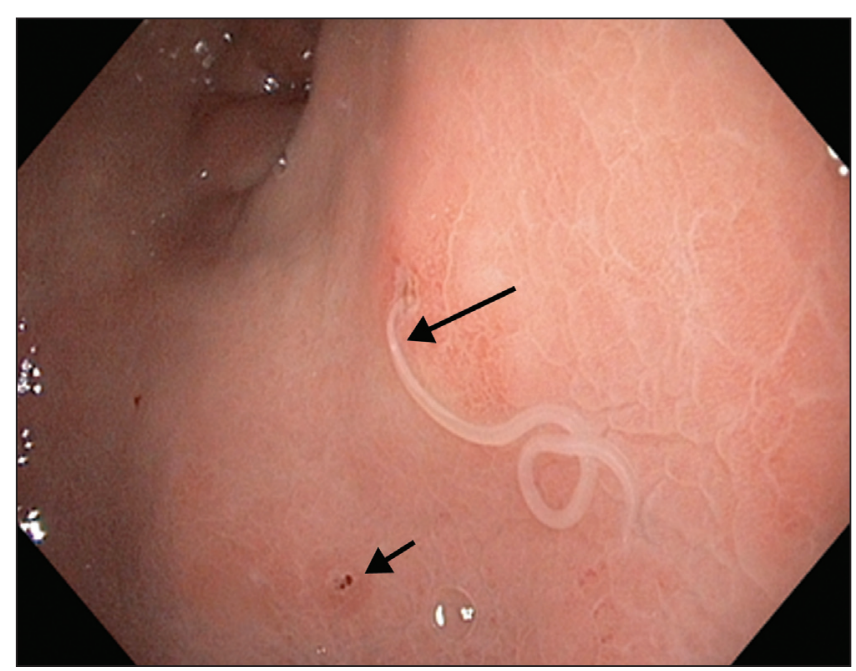

Figure 1) Endoscopic image of stomach demonstrating Anisakis simplex (long arrow) erosion from Anisakis simplex (short arrow)
The patient's epigastric pain resolved the day following the procedure. He received one dose of albendazole $400 \mathrm{mg}$ orally for treatment of probable small bowel anisakiasis. His symptoms resolved completely. A follow-up computed tomography scan six weeks later demonstrated complete resolution of the previously apparent small bowel and gastric findings.

\section{DISCUSSION}

Anisakiasis is a human parasitic disease caused by eating undercooked or raw fish infected with stage 3 larvae of the nematode Anisakis simplex (1). It has been most frequently reported from areas where raw fish is consumed (eg, Japan) (2); however, given the increasing consumption of raw fish globally, has also been recognized in other parts of the world (3).

Gastric anisakiasis usually presents between $1 \mathrm{~h}$ and $12 \mathrm{~h}$ after ingestion of infected fish with the abrupt onset of nausea, vomiting, epigastric pain and low-grade fever (4). As was evident from our case, anisakis larvae may also invade the intestine and patients can present with small bowel obstruction or wall thickening on imaging (5); peripheral eosonophilia is common. Invasion of other gastrointestinal structures (colon, esophagus) is uncommon (6), as is intraperitoneal and pulmonary involvement. Endoscopic findings also include erythema, erosions, ulcerations, submucosal lesions and tumour-like mass (7). Definitive treatment includes removal of any larvae. Albendazole may be particularly effective in the setting of small bowel involvement (8). Prevention is the most important part of management and is achieved by proper cooking to $70^{\circ} \mathrm{C}$ or adequate freezing to $-20^{\circ} \mathrm{C}$ for a minimum of $72 \mathrm{~h}(1)$.

A recent history of eating raw seafood followed by abrupt onset of abdominal pain, nausea, or vomiting and peripheral eosinophilia should raise the suspicion of anisakiasis. Definitive treatment is achieved by removing the parasite endoscopically.

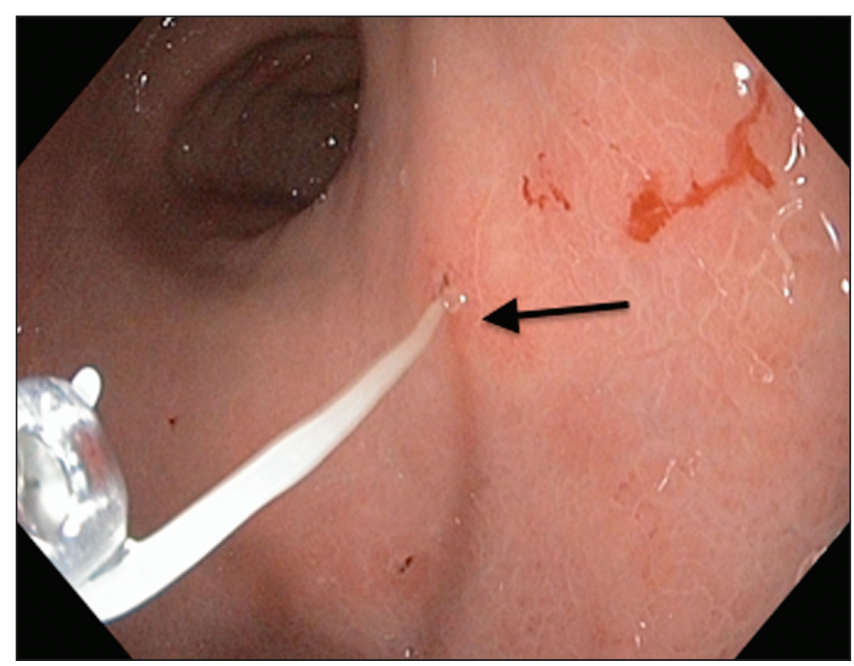

Figure 2) Endoscopic image of stomach demonstrating biopsy forceps removing Anisakis simplex (arrow)

University of Manitoba, Winnipeg, Manitoba

Correspondence: Dr Donald Duerksen, University of Manitoba, 409 Tache Avenue, Winnipeg, Manitoba R2H 2 A6.

Telephone 204 237-2796, fax 204 233-7154, e-mail duerksn@cc.umanitoba.ca

Received for publication November 11, 2012. Accepted November 26, 2012 


\section{REFERENCES}

1. Nawa Y, Hatz C, Blum J. Sushi delights and parasites: The risk of fishborne and foodborne parasitic zoonoses in Asia.

Clin Infect Dis 2005;41:1297-303.

2. Sugimachi K, Inokuchi K, Ooiwa $\mathrm{T}$, et al. Acute gastric anisakiasis. Analysis of 178 cases. JAMA 1985;253:1012-3.

3. Ugenti I, Lattarulo S, Ferrarese F, et al. Acute gastric anisakiasis: An Italian experience. Minerva Chir 2007;62:51-60.

4. Muraoka A, Suehiro I, Fujii M, et al. Acute gastric anisakiasis: 28 cases during the last 10 years. Dig Dis Sci 1996;41:2362-5.

5. Kang DB, Oh JT, Park WC, Lee JK. [Small bowel obstruction caused by acute invasive enteric anisakiasis.] Korean J Gastroenterol 2010;56:192-5.
6. Minamoto T, Sawaguchi K, Ogino T, Mai M. Anisakiasis of the colon: Report of two cases with emphasis on the diagnostic and therapeutic value of colonoscopy. Endoscopy 1991;23:50-2.

7. Kakizoe S, Kakizoe H, Kakizoe K, et al. Endoscopic findings and clinical manifestation of gastric anisakiasis. Am J Gastroenterol 1995;90:761-3.

8. Moore DA, Girdwood RW, Chiodini PL. Treatment of anisakiasis with albendazole. Lancet 2002;360:54.

The Canadian Journal of Gastroenterology is considering a limited number of submissions for IMAGE OF THE MONTH. These are based on endoscopic, histological, radiological and/or patient images, which must be anonymous with no identifying features visible. The patient must consent to publication and the consent must be submitted with the manuscript. All manuscripts should be practical and relevant to clinical practice, and not simply a case report of an esoteric condition. The text should be brief, structured as CASE PRESENTATION and DISCUSSION, and not more than 700 words in length. A maximum of three images can be submitted and the number of references should not exceed five. The submission may be edited by our editorial team. 


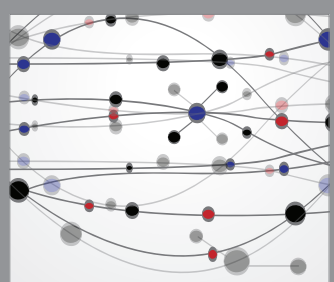

The Scientific World Journal
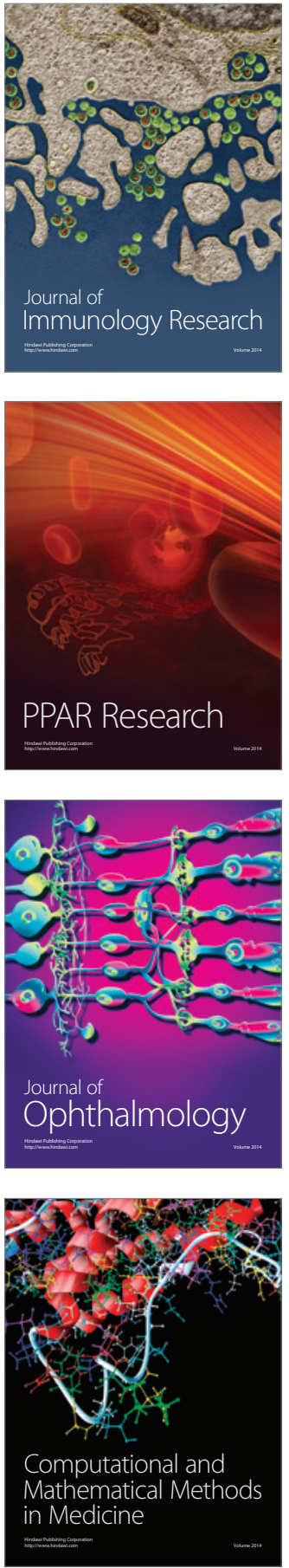

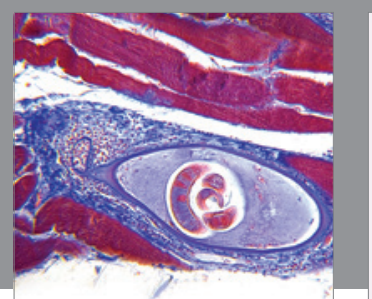

Gastroenterology Research and Practice

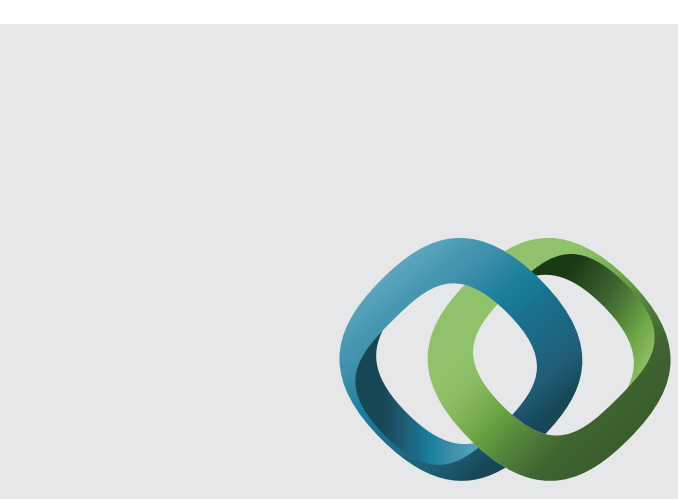

\section{Hindawi}

Submit your manuscripts at

http://www.hindawi.com
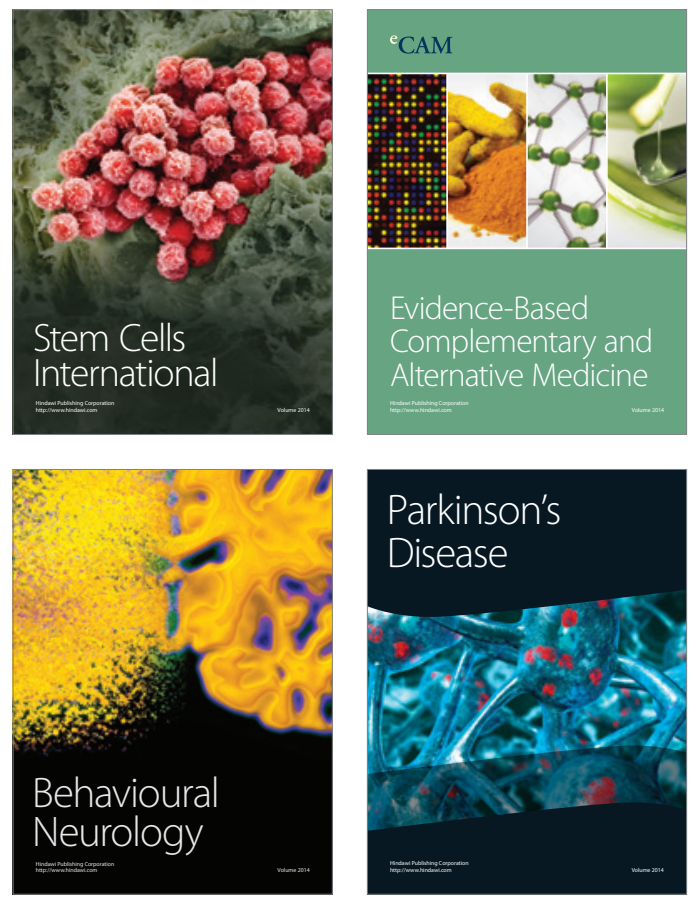
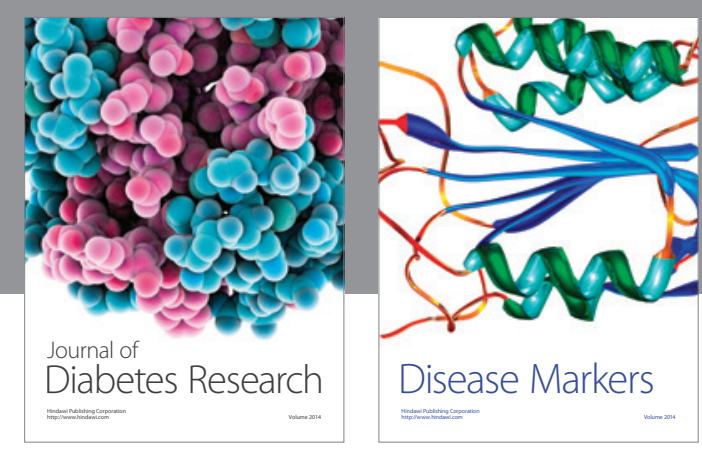

Disease Markers
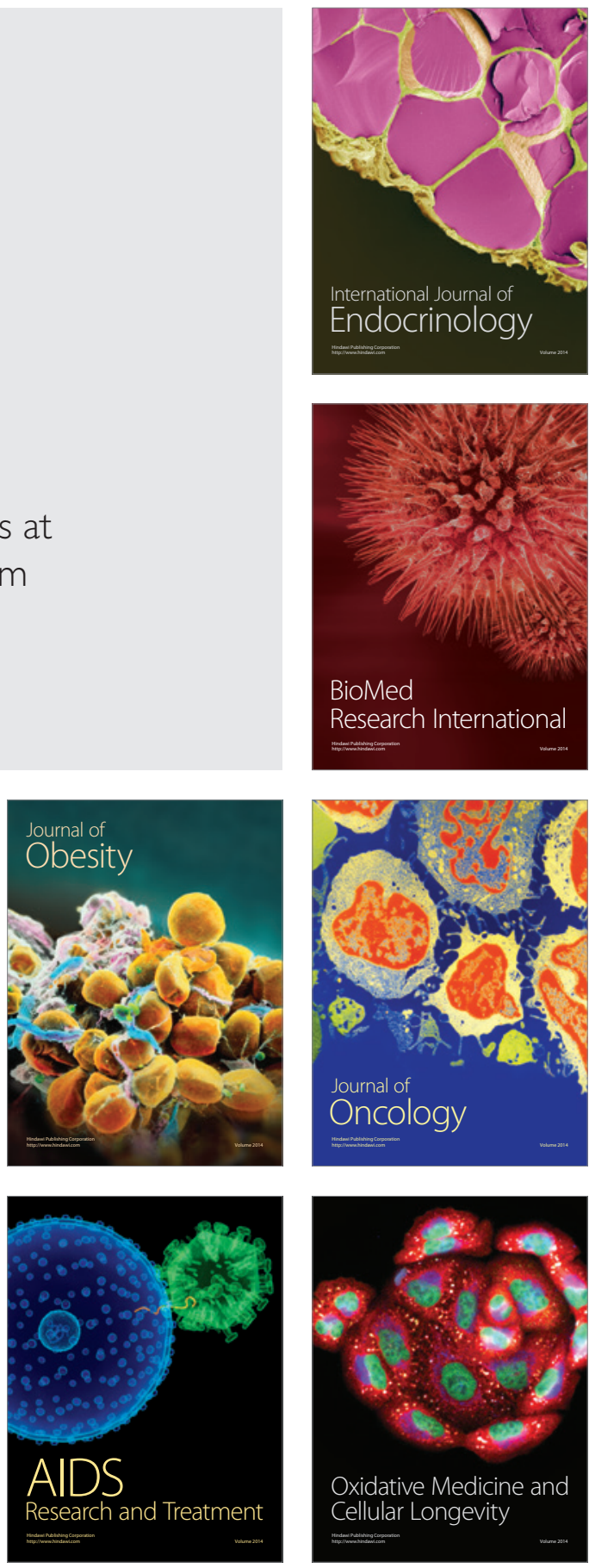